\title{
Why do Sensory Experiences in Autism Vary? An Explanation from Cognitive Linguistics
}

\author{
Huma Batool ${ }^{1} \&$ Wasima Shehzad ${ }^{2}$ \\ ${ }^{1}$ Department of Sciences \& Humanities, National University of Computer and Emerging Sciences, Islamabad, \\ Pakistan; Faculty of English Studies, National University of Modern Languages, Islamabad, Pakistan \\ ${ }^{2}$ Dean, Faculty of Social Sciences, Air University, Islamabad, Pakistan \\ Correspondence: Huma Batool, Department of Sciences \& Humanities, National University of Computer and \\ Emerging Sciences, Islamabad, Pakistan. E-mail: hb.cognistics@gmail.com
}

Received: September 16, 2017 Accepted: September 30, 2017 Online Published: October 25, 2017

doi:10.5539/ijel.v8n1p54 URL: https://doi.org/10.5539/ijel.v8n1p54

\begin{abstract}
Sensory perceptual experiences are now directly associated with the diagnosis of Autism Spectrum Disorder (ASD). Given that autism is a heterogenous disorder, literature abounds in evidences that report varied sensory perceptual issues affecting daily lives of individuals with autism. One question that motivated the current study is "Why do they report to have varied sensory profiles?" The answer lies in the way their bodies interact with the world around them - theory of embodiment in cognitive linguistics. Thirteen children with autism were observed through SPCR (Sensory Profile Checklist Revised (Bogdashina, 2003)) against 20 categories, which Bogdashina (2003) refers to as their bodily resources. Out of seven modalities, only three-vision, hearing and proprioception - were studied for current study. The findings were consistent with the embodiment thesis offered by cognitive linguistics - human beings are embodied beings.
\end{abstract}

Keywords: autism, embodiment, sensory perceptual experiences, sensory processing

\section{Introduction}

The latest edition of the Diagnostic and Statistical Manual of Mental Disorders classifies Autism Spectrum Disorder as a neurodevelopmental disorder that is characterized by following dyad of impairments: limited and affected social communication and interaction (both verbal and non-verbal); and limited repetitive patterns of interests, behaviors and activities (DSM-5TM, 2013). With the refinement of the core features of the disorder, the sensory experiences of individuals with autism also received increased attention — generally and with specific reference to the impact these behaviors/experiences have on the daily lives of people with autism. The DSM-5 thus pronounced sensory behvaiors of individuals with autism as directly associated with the diagnosis of Autism Spectrum Disorder (ASD) and besides different psychometric scales, sensory and perceptual checklists and/or questionnaires are being employed as tools to assess sensory behaviors (Elwin, Schröder, Ek, Wallsten, \& Kjellin, 2017), (Neil, Green, \& Pellicano, 2017) so that autistic-like traits are identified and appropriate intervention strategies are suggested.

Ayres (1985), as quoted in (Ben-Sasson et al., 2009), proclaims human brain as a "sensory processing machine" $-80 \%$ of our nervous system is engaged in processing and/or organizing sensory information. Sensory processing refers to the way sensory input - visual, auditory, proprioceptive, etc., is managed and then used later for action. Dunn (2007) reiterates the environment and the body as the primary sources of sensory input to the brain, and asserts the relationship between sensory processing and human behavior. He further explains sensory processing as a neurological process and the outset of sensory experiences as "neurological thresholds"- the personal range of these sensory thresholds (for noticing and responding) vary from person to person and the nature of these thresholds (low and high) may differ for each sensory input (p. 85). Individuals with autism are reported to face difficulties with processing sensory stimuli thus rendering their sensory experiences to be heterogeneous in nature.

The present study aims to identify the answer of "Why" of their heterogeneity through the individual sensory perceptual profiles of children with autism in the light of their peculiar bodily resources. Bogdashina (2003) asserted that although "they live in the same physical world and deal with the same "raw material", their 
perceptual world turns out to be strikingly different from that of non-autistic people" (p. 44). The reason is their bodily attitude (Monticelli, 2013) and bodily resources which she defined under 20 categories: gestalt perception, intensity of perception, sensitivity to and fascination with certain stimuli, inconsistent perception, fragmented perception, distorted perception, sensory agnosia, delayed perception, sensory overload, monoprocessing, peripheral perception, systems shutdowns, compensation by another sense, resonance, daydreaming, synaesthesia, perceptual memory, associative memory and perceptual thinking (Sensory Profile Checklist Revised (Bogdashina, 2003, p. 184). She refers to these as "autistic experiences" which bring "a different stock of knowledge about the world" (p. 44).

\section{Literature Review}

With specific reference to sensory processing in autism, the studies reported hyper and hypo sensitivity in all modalities where children were reported to encounter sensory difficulties to $80 \%$ in terms of under-responsiveness/seeking of sensations and visual and auditory sensitivity (Baker, Lane, Angley, \& Young, 2008); the prevalence of sensory deficit from 80 to $90 \%$ (Shoener, Kinnealey, \& Koenig, 2008); and the evidence of increased and decreased sensory thresholds (Joosten \& Bundy, 2010).

Baker, Lane, Angley, \& Young (2008) investigated the impact of sensory processing on behavioral responsiveness in autism. They studied 22 children with autism, between the age of 2.9-8.5 years, with the help of few standard checklists-SSP (Short Sensory Profile); VABS (Vineland Adaptive Behavior Scales); and DBC - P (Developmental Behavior Checklist—Parent). The sensory processing dysfunctionality was repoted to be $82 \%$ along with presence of specific pattrens of sensory functioning. The marked impairment was seen in the areas of hyper/hypo sensitivity and auditory filteration.

Horder, Wilson, Mendez, \& Murphy (2014) showed that the traits of autism are associated with sensory experiences and found similar correlation in both genders. They used three different questionnaires, the relevant scores of which coorelated with the the traits of autism. They further proposed a probable integration of sensory processing abnormalities into the diagnosis and assessment of the disorder. The sensory modulations across ages and level of severity are also investigated and the problems are also reported (Ben-Sasson et al., 2009; Elwin, Ek, Schröder, \& Kjellin, 2012).

\subsection{Vision, Hearing and Proprioception in Autism}

Behrmann, Thomas, \& Humphreys (2006) reviewed the perspective of visual perceptual impairment studied from the lenses of ToM deficit, weak central coherence and evidenced perceptual diversifications in autism spectrum disorder. Rondan \& Deruelle (2007) explored visual processing in adults with autism and asperger syndrome and found mixed evidence of both global and local processing. Vandenbroucke, Scholte, Engeland, Lammea, \& Kemner (2009) studied visual processing in autism from the perspective of enhanced perception and found imbalanced visual processing. On the contrary, Remington, Swettenham, Campbell, \& Coleman (2009) found enhanced perceptual capacity and superior visual search ability in autism, and Ashwin, Ashwin, Rhydderch, Howells, \& Baron-Cohen (2009) reported better visual acuity in individuals with autism as compared to control subjects.

Siegal \& Blades (2003); Jones et al. (2009) ; Alcántara, Cope, Cope, \& Weisblatt (2012); O’Connor (2012) studied auditory behaviors and reported varied experiences among their sample. Russo, Mottron, Burack, \& Jemel (2010) and Occelli, Esposito, Venuti, Arduino, \& Zampini (2013) studied auditory and visual sensory and perceptual behaiors and audio-visual integration in autism. They concluded that in autism, these two senses work independently since shift of attention from one modality to another slows down the processing. On the contrary, Keane, Rosenthal, Chun, \& Shams (2010) reported unimpaired auditory-visual integration in high-functioning adults in autism.

Atypical sensory patterns are also found to affect social interaction in individuals with autism (Matsushima \& Kato, 2013). Relevant to proprioceptive processing, individuals with ASD showed proprioceptive difficulties though the results are mixed. Blanche, Reinoso, Chang, \& Bodison (2012) studied proprioception in 32 children with autism through their behavior data. They used Comprehensive Observations of Proprioception (COP) scale and found out distinct patterns of proprioceptive processing. They concluded that proprioceptive difficulties negatively affect participation in daily tasks.

Howe \& Stagg (2016) studied four sensory modalities (vision, hearing, touch and smell) in 14 adults with autism and explored the affect of their sensory experiences on their class room learning. The adult participants with autism reported to experience reduction in concentration-some reported distraction and loss of concentration while listening and some while looking at the visula stimuli, and some in other two modalities. The distraction 
whether auditory or visual, etc., is reported to cause participants lose focus of the classroom and to miss sections of their lessons. They also found inconsistent sensory profiles of all 14 adults-some reported problem in only one modality and while some others in two or all. Another significant finding that they highlighted was that even when some participants reported to experinece sensory problems, they shared thay they do not lose focus and concentration. The differences in sensory processing and varied sensory patterns are also reported by some other other studies (Klintwal et al., 2011; Gomot \& Wicker, 2012; Tomchek, Huebner, \& Dunn, 2014).

The study conducted by Ferna'ndez-Andre's, Pastor-Cerezuela, Sanz-Cervera, \& Ta'rraga-Mı'nguez (2015) confirmed the unpredictable nature of their sensory modalities where sensory processing at home and at school were reported to be different in sample with autism. The probable reason might be what Howe \& Stagg (2016) suggested: in autism, sensory issues are not a constant state - all depends upon the sensory modality that is at work, the nature of sensory input and the situation the person is in at that time.

\subsection{Heterogeneous Sensory Processing and Autism}

This small collection of studies suggest that sensory-perceptual processing in autism is inherently heterogeneous - same individuals were also reported to experience different sensory processing in different contexts. The question arises "Why do their sensory perceptual experiences vary?" To address the issue of heterogeneity in autism, some robust studies (Frith \& Happe, 1994; Baron-Cohen \& Swettenham, 1997; Tager-Flusberg, 2004; Hill, 2004; Pellicano, Maybery, \& Durkin, 2006; Happe' \& Frith, 2006; Skorich, et al., 2015) tried to integrate all three cognitive theories of autism - theory of mind deficit (ToM), weak central coherence (WCC) and executive dysfunction theory. The two alternative theoretical explanations regarding perceptual processes in autism were also suggested by Plaisted and Mottron. Plaisted (2001) proposed theory of Reduced Generalization which suggests that individuals with autism process unique features without any difficulty as compared to common features (p. 13). Mottoron's theory of Enhanced Perceptual Functioning, instead, suggests the presence of superior low-level perceptual processing as a consequence of a specific procsessing bias in autism and accounted perception a superior and different role in autistic cognition (Mottron \& Burack, 2001) exhibit (Mottron, Dawson, Soulières, Hubert, \& Burack, 2006). Nevertheless, it is concluded that none of these can work in unison to satisfy the issues of heterogeniety in autism as they have their own limitaions given the heterogenous nature of the disorder. Given that autism entails different cognitive deficits/styles that result in heterogenous profiles of individuals with autism in terms of their "aetiology, behavioral features, prognosis or response to intervention" (Happe' \& Frith, 2006, p. 15), Rajendran \& Mitchell (2007) pronounced that this might be the reason behind often conflicting results in both intervention and basic reseach studies.

This study tries to answer the "Why" of their heterogeneous sensory experiences through the embodiment theory in cognitive linguistics - the theory provides the framework for the linkage between "low" cognitive processes such as perception and action (sensorimotor experiences) and the bodily resources and bodily attitude (embodiment).

\section{Method}

\subsection{Participants}

Thirteen children with autism (male $=9$; female $=4$ ) were selected for the study. All thirteen children were in middle and late childhood (5-13 years) and were the diagnosed cases of the Autism Resource Centre, Westridge, Rawalpindi. They were diagnosed by the psychologists at the center using Diagnostic Statistical Manual of Mental Disorders (DSM-IV) and Childhood Autism Rating Scale (CARS-2). Two girls and five boys had mild to moderate autism, while two girls and four boys had severe autism. Moreover, the information rich data was acquired not only from the children with autism, but also from their teacher aids and the head teachers. Since the children with autism could not be asked for their willingness, the Autism Resource Centre allowed us to include them as our sample.

The reason for selecting the resource center was that apart from focusing on their academics and speech and language therapy sessions, they have set-ups of "sensory therapy" for the kids with hyper/hypo-sensory modalities and "occupational therapy" for their fine and gross motor training-proprioceptive, vestibular and concept formation activities, etc. Therefore, the staff assigned for each verbal child with autism were a source of detailed information pertaining to the ways the children interact with the world around them. To hide their identity, the subjects' names were replaced with their initials. 


\subsection{Measures}

\subsubsection{Sensory Profile Checklist Revised (SPCR: Bogdashina, 2003)}

The 232-item SPCR-Sensory Profile Checklist Revised (Bogdashina, 2003, p. 184) contains 20 categories (gestalt perception, intensity of perception, sensitivity to and fascination with certain stimuli, inconsistent perception, fragmented perception, distorted perception, sensory agnosia, delayed perception, sensory overload, monoprocessing, peripheral perception, systems shutdowns, compensation by another sense, resonance, daydreaming, synaesthesia, perceptual memory, associative memory and perceptual thinking) to assess the sensory perceptual experiences of individuals with autism in all seven modalities - vision, hearing, proprioception, smell, taste, touch and vestibular (pp. 162-165). For the present study, the SPCR was administered to observe and record the sensory perceptual behaviors of children with autism in only three modalities - vision, hearing and proprioception. The SPCR was then decoded using the key provided (pp. 196-198) and separate tables for all three modalities were composed (Appendix A, Appendix B \& Appendix C) to analyze their behaviors and to explore the possible patterns of perception and processing in all three modalities.

The SPCRs for each verbal child with autism were filled in by their Teacher Aids. We explained the checklists to all thirteen Teacher Aids and requested them to fill in known information and to observe children for the information they themselves were not aware of. After two months, the filled reports were collected and thirteen checklists were discussed in detail, for confirmation of information, with the respective Head Teachers one by one. At some places, Head Teachers pointed out difference of opinion in terms of information provided by Teacher Aids. To resolve the conflicts, we all (Head Teacher, Teacher Aid and researchers) had to discuss the areas of conflict to come to a consensus. The process took another two months due to busy schedule of Head Teachers and Teacher Aids. Some of the information, that was even unknown to both Head Teachers and Teacher Aids, was further confirmed by respective parents/guardians of children.

\section{Results and Discussion}

The findings regarding their diverse, eccentric experiences in all three modalities are calculated as percentages. The percentages against all 20 categories in all three modalities refer to the behaviors that were categorized accordingly in the SPCR (Bogdashina, 2003). For example, out of 54 visual behaviors, 5 indicate visual gestalt, 5 refer to hypervision and 6 to hypovision, 3 indicate presence of visual sensitivity, 1 refers to fascination towards visual stimuli, 1 refers to inconsistent visual fluctuation, 5 tell us about fragmented perception, 5 inform us about distorted perception, 2 indicate sensory agnosia, 2 inform about delayed perception, 1 refers to vulnerability to sensory overload, 1 tell about monoprocessing, 1 about peripheral perception, 2 indicate tendency towards systems shutdowns, and so on. (see Appendix A (Table 1), Appendix B (Table 2), and Appendix C (Table 3) for further explanation).

If few children are reported to have one out of five visual gestalt behaviors, their visual gestalt is calculated as $20 \%$. However, the in-depth qualitative analysis hinted towards different visual behaviors that lead to that $20 \%$ visual gestalt. The following sections discuss the visual, auditory and proprioceptive experiences of all thirteen children with autism one by one in the context of twenty categories of sensory experiences.

\subsection{Findings of Results}

\subsubsection{Visual Experiences}

If we look at the visual embodiment of Az, Wn, An, Ma, Rn, they seemed to have $20 \%$ visual gestalt; however, the in-depth comparison shows that all have different experiences that lead to visual gestalt-Az (severe autism), Ma, An and Rn (mild-moderate autism) notice tiny changes in the environment; Wn (severe autism) does not recognize familiar environment if approached from different direction. On the contrary, Aa (severe autism), Mm, Im, Il (mild-moderate autism) apparently have $40 \%$ visual gestalt and what lead to their visual gestalt is their similar experiences, except for one case-Aa, Il, Mm resist any change while at other times notice tiny change in the environment; Im resists any change in the environment and cannot be fooled by optical illusions.

The comparison of hypervision of An, Zb, Ma, Im, Wn, As, Ah showed similarities and differences despite same percentage- $20 \%$. Wn, Ah (severe autism) and An (mild-moderate autism) cover or squint eyes at bright light while looking intensely at objects and people; Im (severe autism) and $\mathrm{Zb}$ (mild-moderate autism) get scared by sharp flashes of light and lightening, etc.; Ma (mild-moderate autism) constantly looks at minute particles and picks up smallest pieces of fluff; and As (mild-moderate autism) dislikes dark and bright light. Similarly, Az, Mm, $\mathrm{Aa}, \mathrm{Hl}$ and $\mathrm{Il}$ reported to have $40 \%$ hypervision but the experiences that lead to this are somewhat different- $\mathrm{Mm}$ (mild-moderate autism) dislikes dark and bright light and constantly looks at minute particles; Az (severe autism) 
and Il (mild-moderate autism) constantly look at minute particles, pick up smallest pieces of fluff and cover, close or squint eyes at bright light; Aa (severe autism) dislikes dark and bright light and covers, closes or squints eyes at bright light; and $\mathrm{Hl}$ (severe autism) gets scared by sharp flashes of light and closes, covers or squints eyes at bright light.

For hypovision, An, Mm, Hl, Rn, As have displayed 33.33\% hyposensitivity but the experiences that lead to this hyposensitivity are way too different - Mm (mild-moderate autism) is attracted to lights and looks intensely at objects and people; As (mild-moderate autism) gets fascinated with reflections, bright colored objects and runs hands around the edge of the object; An (mild-moderate autism) looks intensely at objects and people, and likes to have perimeter hugging; Rn (mild-moderate autism) gets attracted to light and fascinated with reflections, bright colored objects; and $\mathrm{Hl}$ (severe autism) gets attracted to lights and likes to have perimeter hugging.

For inconsistent perception, sensory overload, monoprocessing and peripheral perception, the findings were quite diverse. Wn, Aa, Im, Ah (severe autism) and Mm, Zb, Ma, An (mild-moderate autism) showed signs of 100\% inconsistent visual perception - they have a tendency to respond to same visual stimuli differently (indifference/pleasure/distress). Az, $\mathrm{Hl}$ (severe autism) and As, Il, Rn (mild-moderate autism) did not report any signs of inconsistent visual perception.

$\mathrm{Az}, \mathrm{Wn}, \mathrm{Hl}$, Ah (severe autism) and Zb, Ma, As (mild-moderate autism) were found to experience $100 \%$ visual overload - all of them either withdraw themselves from visual stimuli or throw tantrums or hurt themselves. Aa, Im (severe autism) and $\mathrm{Mm}, \mathrm{An}, \mathrm{Il}, \mathrm{Rn}$ (mild-moderate autism) do not report to experience visual overload.

Wn, Hl, Ah (severe autism) and As (mild-moderate autism) were reported to experience 100\% monoprocessing - they do not seem to see if listening to something. Az, Aa, Im (severe autism) and Mm, Zb, Ma, An, Il, Rn (mild-moderate autism) did not show any signs of visual monoprocessing.

As for visual peripheral perception, Az, Wn, Aa, Hl, Ah (severe autism) and Mm, As, Rn (mild-moderate autism) displayed $100 \%$ tendency to avoid direct perception. Im (severe autism), and Zb, Ma, An, Il (mild-moderate autism) did not show any signs of visual peripheral perception.

$\mathrm{Az}, \mathrm{Aa}, \mathrm{Hl}, \mathrm{Ah}$ (severe autism) and Rn, An (mild-moderate autism) reported to have $33.33 \%$ tendency to get disturbed by some visual stimuli. All of them either cover or close or squint their eyes in response to sensitive stimuli. Rn, however, gets easily tired/frustrated under fluorescent lights. Wn, and Im (severe autism) and Mm, Zb, Ma, As and Il (mild-moderate autism) were not reported to have any problem with any visual stimuli.

As for systems shutdowns, Az, Wn, Aa, Im, Hl, and Ah (severe autism) and Mm and An (mild-moderate autism) were reported to have a 50\% tendency towards visual whiteouts- $-\mathrm{Wn}$ and Im appear to be mindless followers while $\mathrm{Az}, \mathrm{Aa}, \mathrm{Hl}$, and $\mathrm{Ah}$ surprise with knowing unknown information. However, $\mathrm{Zb}, \mathrm{Ma}$, As and Il (mild-moderate autism) were reported to have experienced $100 \%$ visual whiteouts - they appear to be mindless followers and surprise people with knowing unknown information. Rn (mild-moderate autism) was not found to have such tendency of visual whiteout.

Likewise for sensory agnosia, Az, Wn, Aa, Im (severe autism) and Ma, An, As and Il (mild-moderate autism) were found to have $50 \%$ tendency to experience visual agnosia - Az feels or acts blind while $\mathrm{Wn}, \mathrm{Aa}, \mathrm{Im} \mathrm{Ma}, \mathrm{An}, \mathrm{As}$ and Il display their specific ritualistic behaviors. $\mathrm{Hl}, \mathrm{Ah}$ (severe autism) and $\mathrm{Mm}, \mathrm{Zb}$ (mild-moderate autism) were reported to have $100 \%$ tendency to experience visual agnosia - all of them not only feel or act blind at times but also display their peculiar ritualistic behaviors. Rn (mild-moderate autism) did not seem to experience visual agnosia.

When it comes to fragmented perception, children again showed different experiences with same percentage. Az, $\mathrm{Im}, \mathrm{Hl}$, Ah (severe autism) and As, Il (mild-moderate autism) displayed 20\% experience of fragmented visual perception-Az, Ah, As have a tendency to get lost easily in response to some visual stimuli; Im, Hl, Il resist any visual change in the environment. Wn, Aa (severe autism) and Mm (mild-moderate autism) displayed $40 \%$ visual fragmentation-Wn does not recognize familiar environment if approaches from different direction and gets lost easily; Aa and $\mathrm{Mm}$ resist any visual change and tend to get lost easily in any visual stimuli. $\mathrm{Zb}$ (mild-moderate autism) with $80 \%$ visual fragmentation experiences almost all of the eccentricities - she resists any visual change in the environment, does not recognize people in unfamiliar clothes, selects for attention minor aspects of objects in the environment instead of the whole thing and gets lost easily in some visual stimuli.

The distorted visual perception of the children also highlighted varied experiences. Wn (severe autism) with 20\% of this visual experience was reported to have difficulty catching the ball; Aa, Im, Ah (severe autism) and Mm, Ma, An (mild-moderate autism) showed signs of $40 \%$ distorted visual perception-Aa has difficulty catching the ball and fears heights, stairs and escalators; Im, An face difficulty catching the ball and make compulsive repetitive 
hand, head or body movements; Ah, Ma hit/rub eyes when distressed and make compulsive repetitive hand, head or body movements that fluctuate between near and far; Mm faces difficulty catching ball and hits/rubs eyes when distressed. Az (severe autism), and $\mathrm{Zb}, \mathrm{Rn}$ (mild-moderate autism) were all reported to have $60 \%$ distorted visual perception but their experiences are different- $\mathrm{Az}, \mathrm{Zb}$ find it difficult to catch the ball, hit/rub eyes when distressed and make compulsive hand, body movements that are repetitive and fluctuate between near and far; $\mathrm{Rn}$ has difficulty catching the ball, appears startled when being approached suddenly and fears heights, stairs, escalators. Hl (severe autism) and As (mild-moderate autism) report to have 80\% distortion in visual perception - $\mathrm{Hl}$ has difficulty catching the ball, appears startled when being approached suddenly, hits/rubs eyes when distressed and makes compulsive repetitive hand movements of hand, head and body; As fears heights, stairs, escalators, has difficulty catching the ball, appears startled when behind approached suddenly and makes compulsive, repetitive hand, body and head movements that fluctuate between near and far; Il (mild-moderate autism) does not report to experience any eccentricities in terms of visual distortion.

$\mathrm{Az}, \mathrm{Aa}$ (severe autism) Mm, Zb, An, Il, Rn (mild-moderate autism) did not report to experience delay in perceiving things visually. However, $\mathrm{Hl}$ (severe autism) was reported to experience $100 \%$ delay in visual perception - he responds to visual stimuli late and any experience can be perceived as new and unfamiliar by him, irrespective of the number of times he has experienced them visually. Wn, Im, Ah (severe autism) and Ma, As (mild-moderate autism) experience delayed visual perception to only $50 \%$; the experiences however are different $-\mathrm{Wn}, \mathrm{Ah}$ respond to visual stimuli with a delay; Im, Ma and As perceive any experience as new and unfamiliar no matter how many times they have experienced them.

\subsubsection{Auditory Experiences}

Regarding auditory gestalt, Az (severe autism), As and Il (mild-moderate autism) did not show any signs of auditory gestalt. Wn, Aa, Im, Ah (severe autism) and $\mathrm{Zb}$ (mild-moderate autism) showed $100 \%$ signs of auditory gestalt - they get easily frustrated when they try to do something in a crowded, noisy room and do not seem to understand instructions if more than one person is talking. $\mathrm{Hl}$ (severe autism), Ma and Rn (mild-moderate autism) displayed $50 \%$ auditory gestalt $-\mathrm{Hl}$ gets easily frustrated when he tries to do something in a noisy, crowded room; $\mathrm{Ma}$ and $\mathrm{Rn}$ do not seem to understand instructions if more than one person is talking to them.

There was extreme variation for the intensity with which the hearing of all 13 verbal children with autism was reported to work. Az (severe autism) cannot stand certain sounds and starts making repetitive noises to block out other sounds; however, he likes traffics, crowds and vibration and gets attracted by certain sounds and noises. Wn (severe autism) dislikes sea, thunderstorms, crowds, sounds, noises and haircut while at the same time likes certain other sounds of her choice and likes tearing papers and crumpling them in hands. Aa avoids noises and sounds and covers her ears at many sounds but likes making loud rhythmic noises on her own. Im (severe autism) likes vibration, but on the other hand, avoids sounds and noises of thunderstorm, sea, crowds, etc., and either covers his ears or starts making repetitive noises to block unwanted sounds; he is a very light sleeper and gets frightened by animals. Hl (severe autism) makes loud rhythmic noises on his own, but avoids other disturbing sounds or any noise and either covers his ears or starts making repetitive noises to block out other sounds like Im; he too is a light sleeper, gets frightened by animals and dislikes haircut. Ah (severe autism) likes kitchen, bathroom and vibration, but avoids certain sounds and either covers his ears and/or starts making repetitive noises to block out other sounds; he is also reported to get frightened by animals. Mm (mild-moderate autism) dislikes haircut, crowds, sea and thunderstorm; however, she likes kitchen and bathroom and gets attracted by certain sounds and noises. $\mathrm{Zb}$ (mild-moderate autism) dislikes sea, crowds, thunderstorm and haircut, but gets attracted by sounds/noises, likes vibration, likes to make loud rhythmic noises and to tear and crumple papers. Ma (mild-moderate autism) is a very light sleeper, gets frightened by animals and makes repetitive noises to block out other sounds; on the other hand, he gets attracted by some sounds/noises, makes loud rhythmic noises, bangs objects/doors and likes kitchen and bathroom. An (mild-moderate autism) likes to bang objects and doors, but at the same time he is a light sleeper, and also avoids sounds and noises like crowds, sea, thunderstorm and covers his ears at any other sounds. As (mild-moderate autism) is a light sleeper, avoids noises/sound, dislikes crowds, sea and thunderstorm; he tends to cover his ears at many sounds and sometimes makes repetitive noises to block out other sounds. At other times, he likes vibration, gets attracted by some sounds/noises and makes loud rhythmic noises too. Il (mild-moderate autism) dislikes thunderstorm, crowds, sea and makes repetitive noises to block out other sounds; on the contrary, he also tends to like kitchen, bathroom, traffic and crowds, and gets attracted by sounds and noises. Rn (mild-moderate autism) is reported to dislike haircut and to make repetitive noises to block out other sounds; however, he is also reported to like vibration, crowds and traffic; to bang doors, objects; to get attracted by sounds/noises; and to make loud rhythmic noises.

Except for Az (severe autism) and Il (mild-moderate autism), the rest of children showed diverse range of 
sensitivity to some auditory stimuli. Ma and An (mild-moderate autism) were reported to get extremely (100\%) disturbed by some auditory stimuli- they get frustrated with certain sounds and try to break/destroy if sound comes from any object. Wn, Aa, Im, Hl, Ah (severe autism) and Mm, Zb, As, Rn (mild-moderate autism) were reported to have $50 \%$ tendency to get disturbed by some auditory stimuli; the experiences however vary-Wn, $\mathrm{Aa}, \mathrm{Im}, \mathrm{Hl}, \mathrm{Ah}, \mathrm{Mm}, \mathrm{Zb}$, As get frustrated with certain sounds; Rn tries to destroy /break sound producing objects.

All children except Ma (mild-moderate autism) showed 100\% tendency to get fascinated with some auditory stimuli. As for inconsistent perception, except for $\mathrm{Hl}$ (severe autism) and Rn (mild-moderate autism), all other children showed signs of $100 \%$ inconsistency for auditory perception - they may respond differently (distress/pleasure/indifference) to same auditory stimuli (noises/sounds).

$\mathrm{Az}, \mathrm{Wn}, \mathrm{Aa}, \mathrm{Im}, \mathrm{Hl}, \mathrm{Ah}$ (severe autism) and $\mathrm{Zb}$, As (mild-moderate autism) showed $100 \%$ tendency to experience auditory overload - they experience sudden outburst of self-abuse or throw tantrums or withdraw themselves in response to auditory stimuli. Mm, Ma, An, Il and Rn (mild-moderate autism) were not reported to have experienced auditory overload.

$\mathrm{Az}, \mathrm{Im}$ (severe autism) and $\mathrm{Zb}$, Ma, An, As (mild-moderate autism) were reported to experience $50 \%$ sensory agnosia-Az feels/acts deaf; Im, Zb, Ma, An, As get engaged in their particular ritualistic behaviors. Rn and Il do not report to experience auditory agnosia.

$\mathrm{Zb}$, Ma, As (mild-moderate autism) displayed $100 \%$ signs of auditory shutdowns - they all appear to be mindless followers and surprise others with knowing unknown information. On the other hand, Az, Wn, Aa, Im, Hl, Ah (severe autism) and Mm, An (mild-moderate autism) displayed 50\% signs of auditory shutdowns-Az, Aa, Hl, $\mathrm{Ah}, \mathrm{Mm}$, An surprise with knowing unknown information; Wn and Im appear to be mindless followers. Rn and Il do not report to experience auditory shutdowns.

$\mathrm{Az}, \mathrm{Aa}, \mathrm{Hl}$ (severe autism) and Il (mild-moderate autism) did not report to experience any auditory distorted perception. Wn (severe autism) and $\mathrm{Zb}$, An, As (mild-moderate autism) were reported to have $66.67 \%$ of auditory distorted perception - all of them have pronunciation problems and cannot distinguish between some sounds, except for An who hits ears when distressed and has pronunciation problems. Im, Ah (severe autism), and $\mathrm{Mm}, \mathrm{Ma}$, Rn (mild-moderate autism) reported $33.33 \%$ tendency to experience auditory distorted perception - Im, Ah hit ears when distressed; Mm, Ma, Rn have pronunciation problems.

Regarding fragmented perception, Az, Wn, Aa (severe autism) and Mm, An, Il, Rn (mild-moderate autism) did not show any signs of fragmented hearing. On the other hand, Im, Hl, Ah (severe autism) and $\mathrm{Zb}, \mathrm{Ma}$, As (mild-moderate autism) were reported to experience auditory fragmented perception - they have a tendency to hear few words instead of the whole sentence.

$\mathrm{Mm}, \mathrm{Zb}$, Il (mild-moderate autism) did not report any signs of delayed audition. However, Az, Aa, Ah (severe autism) and Rn (mild-moderate autism) showed 33.33\% tendency to have delayed hearing-all of them respond to questions, instructions and sounds with a delay. Wn, Im (severe autism) and An, As (mild-moderate autism) with apparent $66.67 \%$ delayed audition have different experiences-Wn, An experience echolalia in high-pitched, monotonous, parrot-like voice and respond to instructions, questions and sounds with a delay; Im, As produce echolalia in monotonous, high-pitched, parrot-like voice and to them, any experience can become new an unfamiliar, irrespective of the number of times they have experienced the same thing.

\subsubsection{Proprioceptive Experiences}

Wn (severe autism) and Mm, Ma, An, Il, Rn (mild-moderate autism) did not report any signs of proprioceptive gestalt. However, the rest of them-Az, Aa, Im, Hl, Ah (severe autism) and Zb, As (mild-moderate autism) are found to experience $100 \%$ proprioceptive gestalt: they all are clumsy and move stiffly.

The proprioceptive sense of Az, Aa, Im (severe autism), and Zb, Ma, As (mild-moderate autism) was 33.33\% hypo-Az, Im, Ma they turn the whole body to look at something; Aa, Zb, As observe odd body posturing. Hl, $\mathrm{Ah}$ (severe autism) and Mm (mild-moderate autism) reported to have hypo-proprioception of about $66.67 \%-\mathrm{Hl}$, Ah observe odd body posturing and have difficulty manipulating small objects; Mm observes odd body posturing and turns the whole body to look at something. Wn (severe autism), An, Il and Rn (mild-moderate autism) do not report to have hypo-proprioception.

As for the findings pertaining to hyper-proprioception, almost all of them showed varied signs. The proprioception of Az, Wn, Ah (mild-moderate autism) is hypo to 37.5\%-Az has low muscle tone, often leans against people, furniture, wall and rocks back and forth; Wn does not sense her body sensations, bumps into objects and people, and often leans against people/furniture/walls; Ah is unaware of his body position in space, 
bumps into objects, people and appears floppy. Im, Hl (severe autism), Il (mild-moderate autism) experience $12.5 \%$ hypo-proprioception - Im bumps into objects, people; Hl often leans against people, furniture, walls; Il experiences lack of awareness of his body position in space. Aa (severe autism) and Ma (mild-moderate autism) showed 25\% hypo-proprioception - both bump into people, objects and often lean against people/furniture/walls. $\mathrm{Zb}$, As (mild-moderate autism) were reported to have $50 \%$ hypo-proprioception- $\mathrm{Zb}$ is unaware of her body position and sensations, often leans against people/furniture/walls and rocks back and forth; As has low muscle tone, lack of awareness of his body position in space, bumps into objects/people and rocks back and forth. Only three children-Mm, An and Rn (mild-moderate autism) - did not report to experience any hyposensitive proprioception.

$\mathrm{Aa}, \mathrm{Hl}$, Ah (severe autism) and As (mild-moderate autism) were found to get $100 \%$ disturbed by some stimuli - they cannot tolerate certain movements/body positions. The rest of them-Az, Wn, Im (severe autism) and $\mathrm{Mm}, \mathrm{Zb}, \mathrm{Ma}, \mathrm{An}, \mathrm{Il}, \mathrm{Rn}$ (mild-moderate autism) — did not show any such signs of proprioceptive disturbance.

$\mathrm{Az}, \mathrm{Wn}, \mathrm{Im}, \mathrm{Ah}$ (severe autism) and $\mathrm{Zb}, \mathrm{Ma}$ (mild-moderate autism) showed $100 \%$ fascination towards some body movements - they all are often engaged in complex body movements, especially when they are bored or frustrated. The rest of them-Aa, Hl (severe autism), Mm, An, Il, Rn (mild-moderate autism) did not show any such fascination.

As for sensory agnosia, only As (mild-moderate autism) showed 100\% tendency to experience proprioceptive agnosia - he does not seem to know what his body is doing.

$\mathrm{Az}, \mathrm{Aa}, \mathrm{Im}$ (severe autism) and $\mathrm{Zb}$, An, As (mild-moderate autism) displayed 100\% tendency to experience proprioceptive overload - they get tired easily especially when standing or when in noisy, bright places. The rest of them did not show any such signs of overload.

None of them showed any signs of proprioceptive shutdowns.

As for fragmented proprioception, only $\mathrm{Zb}$ and $\mathrm{An}$ (mild-moderate autism) showed signs of $100 \%$ fragmentation - both of them complain about their limbs and body parts. The rest of them did not report to experience any such fragmentation.

For distorted proprioception, Az, Wn, Aa, Im (severe autism) and Mm, As, Rn (mild-moderate autism) showed $50 \%$ signs of distorted proprioception - they all have difficulty catching the ball. $\mathrm{Hl}$ (severe autism) and $\mathrm{Zb}, \mathrm{An}$ (mild-moderate autism) reported $100 \%$ distorted proprioception - they have difficulty catching the ball and with jumping, hopping, riding tri/bicycle. Ah (severe autism) and Ma, Il (mild-moderate autism) displayed no signs of distorted proprioception.

$\mathrm{Az}, \mathrm{Hl}$ (severe autism) and $\mathrm{Mm}, \mathrm{Zb}$ (mild-moderate autism) displayed $100 \%$ tendency of delayed proprioception - they all are very poor at sports. The rest of them did not show any such tendencies.

\subsection{Discussion}

\subsubsection{Heterogeneity is due to Varied Embodiment}

We all interact with the world and process information through our senses (Burr \& Gori, 2011). This process of taking in of information via senses has been described as perception by Bogdashina (2005): "Perception is the process by which an organism collects, interprets and comprehends information from the outside world by means of the senses" (p. 44). This perspective dismisses the idea of mind as a machine which only stores and retrieves information; it is an active being that constantly interacts with the outer world via our bodies. Experience is not limited to passive reception through senses-it entails complex interactions that make up our understanding of the world around us (Johnson, 1987).

The cross-case findings of visual, auditory and proprioceptive experiences of all 13 children with autism are consistent with the Cognitive Linguistics perspective of experientialism and varied embodiment, and very clearly answer the "Why" of their heterogeneous sensory profiles - they also experience, perceive, think, and feel differently like other embodied beings (neurotypicals) and the way they process information depends upon their unique yet limited bodily resources. In the words of Evans \& Green (2006), "Our construal of reality is likely to be mediated in large measure by the nature of our bodies." (p. 45).

Findings of the behavior data highlighted the different and unique patterns of sensory perceptual experiences of children with autism - visual, auditory and proprioceptive embodiment. The findings verify the findings of the robust empirical and behavior studies (e.g., Behrmann, Thomas, \& Humphreys, (2006); Remington, Swettenham, Campbell, \& Coleman (2009); Baker, Lane, Angley, \& Young (2008) that highlighted the processing problems 
that the individuals with autism encounter. Furthermore, since comparison of all 13 children with same autism diagnosis have displayed different personalities, strengths and weaknesses, the findings are consistent with the studies that evidenced autism as a bunch of complex and heterogenous developmental disorder (Chouinard, Noulty, Sperandio, \& Landry, 2013; Tager-Flusberg, 2007). Though the studies were conducted from the perspective of cognitive psychology, they ascertained that the eccentricities in perception and processing contribute to their different experiences. The findings were considerably consistent with what Bogdashina (2003) asserted - these "autistic experiences" bring "a different stock of knowledge about the world" (p. 44). Their limited resources and unique/different bodily attitude render them a leeway to a different world of experience. That different experience results in different embodiment. Hence, their limited and different bodily resources are the reason of their varied sensory perceptual experiences.

Furthermore, while confirming the link between autism and sensory experiences, Horder, Wilson, Mendez, \& Murphy (2014) suggested that sensory traits could potentially measure the severity of autism. Baker, Lane, Angley, \& Young (2008) also found a correlation between severe sensory processing problems and severe symptoms of autism. However, the findings of the current study did not show this kind of correlation-between sensory experiences and the severity of autism. The severity of autism did not show any effect on their relevant sensory experiences. It was their varied embodiment that was found to play a determining role.

By giving examples of the experiments conducted by developmental psychologists, to figure out how babies utilize their bodies to learn initial concepts like stepping, etc., Barrett (2011) rested his case: since all bodies are not the same, "[w]e learn how to exploit our specific bodily resources, and that requires "customized" learning strategies and developmental trajectories" (p. 177). Hence, our "specific bodily resources" offer distinct kind of embodiment in the context of which "we all see the world in our distinctively human like way" (p. 176).

Cognitive Linguistics explains and establishes human beings as "embodied beings"-our bodies negotiate with the world to construct our own versions of reality in the contexts of our varied bodily, sensory, perceptual experiences (Tyler \& Evans, 2003). Evans \& Greens (2006) proposed this situation as "varied embodiment" (p. 45). Every action is then embodied action and our different physical and pre-conceptual (sensory-perceptual) experiences are in fact "varied embodiment in action" and serve as the basis of our subjective construal of the world. Monticelli (2013) cites Plessner's idea of bodily involvement in perceptual experience and the part that our bodies play to construct sensory world as "bodily attitude" (p. 39). This dynamic experience where body is the prime mediator is referred to as "embodied experience" (Lakoff, 2015; Lakoff, 2013). This rich notion of experience entails diverse dimensionality and renders varied embodiment of children with autism a fundamental place in understanding and grasping their world.

To resume, our findings suggest that individuals with autism are also embodied beings. Whether their sensory processing is enhanced, biased, local or global or a combination of these styles, it is their unique yet limited bodily involvement that constructs their experiences accordingly. We assert that the product of their processing should be regarded as embodied processing. This new lens of "embodiment" will help looking at autism not as a cognitive deficit but a cognitive style in the same way as Bogdashina (2010) suggests: "There is by no means a dysfunctional world. It is rather a completely different world" (p. 24).

\section{Conclusion}

We conclude the study while putting forward some practical suggestions:

1) The SPCR is a comprehensive guide that allows to look deep into all seven modalities to identify possible sensory perceptual patterns in individuals with autism. The practitioners, parents and professionals can use it to devise intervention and education strategies for individuals with autism despite their age, gender and level of autism.

2) Embodied cognition thesis in Cognitive Linguistics posits that different experiences lead to "variable embodiment" (Evans \& Green, 2006), where everyone conceptualizes, construes and constructs his/her own meaning. The thesis of embodied cognition also holds that our mental representations (conceptual structures) are affected by pre-conceptual (sensory) experiences. Our bodily experiences provide us with "lens" which helps us to give words to certain concepts. These propositions were applied on the behaviors of children with autism and for future research, can be applied on the language of children with autism to see if their concepts window something about their embodiment. The embodiment theory in Cognitive Linguistics provides the framework for the linkage between "low" cognitive processes such as perception and action (sensorimotor experiences), and "high" cognitive processes, such as language language and thought (Jirak, Menz, Buccino, Borghi, \& Binkofski, 2010). Given their unique embodiment, the future research can look at their language and thought from the same perspective. 
3) Experience of children with autism as "autistic experience" also define their embodiment in different aspects. They are "children with autism" and this is their identity. This identity entails a list of traits that define their unique experiences - different experience of social initiation and response, different experience of non-verbal communication, different experience of social awareness and social relationships, different experience in terms of behavior, interests and activities, different interaction with objects, different sensory experiences. Hence, other traits of autism can be viewed using the lenses of embodiment.

\section{References}

Alcántara, J. I., Cope, T. E., Cope, W., \& Weisblatt, E. J. (2012). Auditory temporal-envelope processing in high-functioning children with Autism Spectrum Disorder. Neuropsychologia, 1235-1251. https://doi.org/10.1016/j.neuropsychologia.2012.01.034

Ashwin, E., Ashwin, C., Rhydderch, D., Howells, J., \& Baron-Cohen, S. (2009). Eagle-Eyed Visual Acuity: An Experimental Investigation of Enhanced Perception in Autism. Biological Psychiatry, 65, 17-21. https://doi.org/10.1016/j.biopsych.2008.06.012

Ayres, J. A. (1985). Developmental dyspraxia and adult onset. Torrance, CA: Western Psychological Services.

Baker, A. E., Lane, A., Angley, M. T., \& Young, R. L. (2008). The Relationship Between Sensory Processing Patterns and Behavioural Responsiveness in Autistic Disorder: A Pilot Study. J Autism Dev Disord, 867-875. https://doi.org/10.1007/s10803-007-0459-0

Baron-Cohen, S., \& Swettenham, J. (1997). Theory of mind in autism: its relationship to executive function and central coherence. In D. Cohen, \& F. Volkmar (Eds.), Handbook of Autism and Pervasive Developmental Disorders (2nd ed.). New York: John Wiley and Sons. Retrieved from https://www.researchgate.net/profile/Simon_Baron-Cohen/publication/238794390_Theory_of_mind_in_aut ism_its_relationship_to_executive_function_and_central_coherence/links/5475f2d00cf245eb43714198/The ory-of-mind-in-autism-its-relationship-to-executive-functi

Barrett, L. (2011). Beyond the brain: how body and environment shape animal and human minds. Princeton and Oxford: Princeton University Press.

Behrmann, M., Thomas, C., \& Humphreys, K. (2006). Seeing it differently: visual processing in autism. TRENDS in Cognitive Sciences, 10(6), 258-264. https://doi.org/10.1016/j.tics.2006.05.001

Ben-Sasson, A., Hen, L., Fluss, R., Cermak, S. A., Engel-Yeger, B., \& Gal, E. (2009). A Meta-Analysis of Sensory Modulation Symptoms in Individuals with Autism Spectrum Disorders. J Autism Dev Disord, 1-11. https://doi.org/10.1007/s10803-008-0593-3

Blanche, E. I., Reinoso, G., Chang, M. C., \& Bodison, S. (2012, September/October). Brief Report: Proprioceptive processing difficulties among children with autism spectrum disorders and developmenla disabilities. American Journal of Occupational Therapy, 621-624. https://doi.org/10.5014/ajot.2012.004234

Bogdashina, O. (2003). Sensory perceptual issues in autism and asperger syndrome: different sensory experiences - different perceptual world. London; New York: Jessica Kngsley Publishers.

Bogdashina, O. (2005). Communication issues in Autism and Asperger syndrome: do we speak the same language? London and Philadelphia: Jessica Kingsley Publishers.

Bogdashina, O. (2010). Autism and the edges of the known world: Sensitivities, Language and Constructed Reality. London and Philadelphia: Jessica Kingsley Publishers.

Burr, D., \& Gori, M. (2011). Multisensory Integration Develops Late in Humans. In M. T. Murray, \& M. M. Wallace (Eds.), The Neural Bases of Multisensory Processes (pp. 345-362). Boca Raton: CRC Press. https://doi.org/10.1201/9781439812174-23

Chouinard, P. A., Noulty, W. A., Sperandio, I., \& Landry, O. (2013). Global processing during the MulleLyer illusion is dictinctively affected by the degree of autistic traits in the typical population. Exp Brain Res, 219-231. https://doi.org/10.1007/s00221-013-3646-6

Collignon, O., Charbonneau, G., Peters, F., Nassim, M., Lassonde, M., Lepore, F., ... Bertone, A. A. (2013). Reduced multisensory facilitation in persons with autism. Cortex, 1704-1710. https://doi.org/10.1016/j.cortex.2012.06.001

Dunn, W. (2007). Supporting children to participate successfully in everyday life by using sensory processing knowledge. Infants \& Young Children, 84-101. https://doi.org/10.1097/01.IYC.0000264477.05076.5d 
Elwin, M., Ek, L., Schröder, A., \& Kjellin, L. (2012). Autobiographical Accounts of Sensing in Asperger Syndrome and High-Functioning Autism. Archives of Psychiatric Nursing, 420-429. https://doi.org/10.1016/j.apnu.2011.10.003

Elwin, M., Schröder, A., Ek, L., Wallsten, T., \& Kjellin, L. (2017). Sensory Clusters of Adults With and Without Autism Spectrum Conditions. Jjournal of Autism and Developmental Disorders, 579-589. https://doi.org/10.1007/s10803-016-2976-1

Evans, V., \& Green, M. (2006). Cognitive linguistics: an introduction. Edinburgh: Edinburgh Uuniversity Press.

Ferna'ndez-Andre's, M. I., Pastor-Cerezuela, G., Sanz-Cervera, P., \& Ta'rraga-Mínguez, R. (2015). A comparative study of sensory processing in children with and without Autism Spectrum Disorder in the home and classroom environments. Research in Developmental Disabilities, 202-212. https://doi.org/10.1016/j.ridd.2014.12.034

Frith, U., \& Happe, F. (1994). Autism: beyond "theory of mind". Cognition, 115-132. https://doi.org/10.1016/0010-0277(94)90024-8

Gomot, M., \& Wicker, B. (2012). A challenging, unpredictable world for people with Autism Spectrum Disorder. International Journal of Psychophysiology, 240-247. https://doi.org/10.1016/j.ijpsycho.2011.09.017

Happe', F., \& Frith, U. (2006, January). The Weak Coherence Account: Detail-focused Cognitive Style in Autism Spectrum Disorders. Journal of Autism and Developmental Disorders, 36(1), 5-25. https://doi.org/10.1007/s10803-005-0039-0

Hill, E. E. (2004). Evaluating the theory of executive dysfunction in autism. Developmental Review, 189-233. https://doi.org/10.1016/j.dr.2004.01.001

Horder, J., Wilson, C. E., Mendez, M. A., \& Murphy, D. G. (2014). Autistic traits and abnormal sensory experiences in adults. J. Autism Dev Disorder, 1461-1469. https://doi.org/10.1007/s10803-013-2012-7

Howe, F. E., \& Stagg, S. D. (2016). How Sensory Experiences Affect Adolescents with an Autistic Spectrum Condition within the Classroom. Journal for Autism and Developmental Disorders, 1656-1668. https://doi.org/10.1007/s10803-015-2693-1

Jirak, D., Menz, M. M., Buccino, G., Borghi, A. M., \& Binkofski, F. (2010). Grasping language-A short story on embodiment. (E. Inc., Ed.) Consciousness and Cognition, 711-720. https://doi.org/10.1016/j.concog.2010.06.020

Johnson, M. (1987). The body in the mind: the bodily basis of meaning, imagination and reason. Chicago \& London: The University of Chicago Press.

Jones, C. R., Happé, F., Baird, G., Simonoff, E., Marsdene, A. J., Jenifer Tregaye, R. J., ... Charman, T. (2009). Auditory discrimination and auditory sensory behaviours in autism spectrum disorders. Neuropsychologia, 2850-2858. https://doi.org/10.1016/j.neuropsychologia.2009.06.015

Joosten, A. V., \& Bundy, A. C. (2010). Sensory processing and stereotypical and repetitive behaviour in children with autism and intellectual disability. Australian Occupational Therapy Journal, 366-372. https://doi.org/10.1111/j.1440-1630.2009.00835.x

Keane, B. P., Rosenthal, O., Chun, N. H., \& Shams, L. (2010). Audiovisual integration in high functioning adults with autism. Research in Autism Spectrum Disorders, 276-289. https://doi.org/10.1016/j.rasd.2009.09.015

Klintwal, L., Holm, A., Eriksson, M., Carlsson, L. H., Olsson, M. B., Hedvall, A., ... Fernell, E. (2011). Sensory abnormalities in autism: A brief report. Research in Developmental Disabilities, 795-800. https://doi.org/10.1016/j.ridd.2010.10.021

Lakoff, G. (2013). You Tube PK. Retrieved from https://www.youtube.com/watch?v=XWYaoAoijdQ

Lakoff, G. (2015). You Tube PK. Retrieved from https://www.youtube.com/watch?v=WuUnMCq-ARQ

Matsushima, K., \& Kato, T. (2013). Social Interaction and Atypical Sensory Processing in Children with Autism Spectrum Disorders. Hong Kong Journal of Occupational Therapy, 89-96. https://doi.org/10.1016/j.hkjot.2013.11.003

Monticelli, R. D. (2013). Embodied Visual Perception. An Argument from Plessner (1923)*. Phenomenology and Mind, 35-46. http://dx.doi.org/10.13128/Phe_Mi-19585 
Mottron, L., \& Burack, J. (2001). Enhanced perceptual functioning in the development of autism. In J. A. Burack, T. Charman, N. Yirmiya, \& P. R. Zelazo (Eds.), The development of autism: perspectives from theory and research (pp. 131-148). Mahwah, New Jersay; London: Lawrence Erlbaum Associates, Publishers.

Mottron, L., Dawson, M., Soulières, I., Hubert, B., \& Burack, J. (2006). Enhanced Perceptual Functioning in Autism: An Update, and Eight Principles of Autistic Perception. Journal of Autism and Developmental Disorders, 36(1), 27-43. https://doi.org/10.1007/s10803-005-0040-7

Neil, L., Green, D., \& Pellicano, E. (2017). The Psychometric Properties of a New Measure of Sensory Behaviors in Autistic Children. Journal of Autism and Developmental Disorders, 1261-1268. https://doi.org/10.1007/s10803-016-3018-8

O'Connor, K. (2012). Auditory processing in autism spectrum disorder: A review. Neuroscience and Biobehavioral Reviews, 836-854. https://doi.org/10.1016/j.neubiorev.2011.11.008

Occelli, V., Esposito, G., Venuti, P., Arduino, G. M., \& Zampini, M. (2013). Attentional shifts between audition and vision in Autism Spectrum Disorders. Research in Autism Spectrum Disorders, 517-525. https://doi.org/10.1016/j.rasd.2012.12.003

Pellicano, E., Maybery, M., \& Durkin, K. (2006). Multiple cognitive capabilities/deficits in children with an autism spectrum disorder: "Weak" central coherence and its relationship to theory of mind and executive control. Development and Psychopathology, 77-98. https://doi.org/10.1017/S0954579406060056

Plaisted, K. C. (2001). Reduced Generalization in Autism:. In J. A. Burack, T. Charman, N. Yirmiya, \& P. R. Zelazo (Eds.), The development of Autism: Perspectives from Theory and Research (pp. 149-169). New Jersey: Lawrence Erlbaum Associates, Inc, Publishers.

Rajendran, G., \& Mitchell, P. (2007). Cognitive theories of autism. Developmental Review, 224-260. https://doi.org/10.1016/j.dr.2007.02.001

Remington, A., Swettenham, J., Campbell, R., \& Coleman, M. (2009). Selective Attention and Perceptual Load in Autism Spectrum Disorder. Psychological Science, 1-6. https://doi.org/10.1111/j.1467-9280.2009.02454.x

Rondan, C., \& Deruelle, C. (2007). Global and configural visual processing in adults with autism and Asperger syndrome. Research in Developmental Disabilities, 197-206. https://doi.org/10.1016/j.ridd.2006.02.007

Russo, N., L.Mottron, J.A.Burack, \& B.Jemel. (2010). Parameters ofsemantic multisensory integration depend on timing and modality order among people on the autism spectrum: Evidence from event-related potentials. Neuropsychologia, 2131-2141.

Sedal, D. L. (2013). Diagnostic and statistical manual of mental disorders. (5th ed.). Washington, DC; London, England: American Psychiatric Association.

Shoener, R. F., Kinnealey, M., \& Koenig, K. P. (2008). You can know me now if you listen: sensory, motor and communication issues in a nonverbal person with autism. The American Journal of Occupational Therapy, 547-553. https://doi.org/10.5014/ajot.62.5.547

Siegal, M., \& Blades, M. (2003). Language and auditory processing in autism. TRENDS in Cognitive Sciences, 378-380. https://doi.org/10.1016/S1364-6613(03)00194-3

Skorich, D. P., May, A. R., Talipski, L. A., Hall, M. H., Dolstra, A. J., Gash, T. B., \& Gunningham, B. H. (2015, Oct). Is Social Categorization the Missing Link Between Weak Central Coherence and Mental State Inference Abilities in Autism? Preliminary Evidence from a General Population Sample. J Autism Dev Disord, 862-881.

Tager-Flusberg, H. (2007). Evaluating the Theory-of-Mind hypothesis of autism. Current Directions in Psychological Science, 16(6), 311-315. https://doi.org/10.1111/j.1467-8721.2007.00527.x

Tager-Flusberg, R. M. (2004, Sep). The relationship of theory of mind and executive functions to symptom type and severity in children with autism. Dev Psychopathol, 16(1), 137-155.

Tomchek, S. D., Huebner, R. A., \& Dunn, W. (2014). Patterns of sensory processing in children with an autism spectrum disorder. Research in Autism Spectrum Disorders, 1214-1224. https://doi.org/10.1016/j.rasd.2014.06.006 
Tyler, A., \& Evans, V. (2003). The Semantics of English Prepositions: Spatial Scenes, Embodied Meaning and Cognition. Cambridge, New York, Melbourne, Madrid, Cape Town, Singapore, São Paulo: Cambridge University Press. https://doi.org/10.1017/CBO9780511486517

Vandenbroucke, M. W., Scholte, H. S., Engeland, H. v., Lammea, V. A., \& Kemner, C. (2009). A new approach to the study of detail perception in Autism Spectrum Disorder (ASD): Investigating visual feedforward, horizontal and feedback processing. Vision Research, 1006-1016. https://doi.org/10.1016/j.visres.2007.12.017

\section{Appendix A}

Table 1. Possible patterns of visual experiences (adapted from (Bogdashina, 2003))

\begin{tabular}{|c|c|c|c|}
\hline No. & Sensory Experiences & Behaviors & \\
\hline \multirow[t]{5}{*}{1.} & Gestalt Perception & 1. & Resists any change \\
\hline & (Inability to filter visual stimuli) & 2. & Notices any tiny change in the environment \\
\hline & & 3. & $\begin{array}{l}\text { Does not recognize a familiar environment if approaches it from a } \\
\text { different direction }\end{array}$ \\
\hline & & 4. & Does not recognize people in unfamiliar clothes \\
\hline & & 5. & Is not fooled by optical illusions \\
\hline \multirow[t]{13}{*}{2.} & Intensity with which senses work & Hyper: & \\
\hline & & 1. & $\begin{array}{l}\text { Constantly looks at minute particles, picks up smallest pieces of } \\
\text { fluff }\end{array}$ \\
\hline & & 2. & Dislikes dark and bright lights \\
\hline & & 3. & Is frightened by sharp flashes of light, lightening, etc. \\
\hline & & 4. & Looks down most of the time \\
\hline & & 5. & Covers, closes, or squint eyes at bright light \\
\hline & & Hypo: & \\
\hline & & 1. & Is attracted to lights \\
\hline & & 2. & Looks intensely at objects and people \\
\hline & & 3. & Moves fingers or objects in front of eyes \\
\hline & & 4. & Is fascinated with reflections, bright coloured objects \\
\hline & & 5. & Runs a hand around the edge of the object \\
\hline & & 6. & Perimeter hugging \\
\hline \multirow[t]{3}{*}{3.} & Sensitivity to (disturbance by) some stimuli & 1. & Covers, closes, or squint eyes at bright light \\
\hline & (Light/colour sensitivity; & 2. & Gets easily frustrated/tired under fluorescent lights \\
\hline & Disturbance by some patterns) & 3. & Gets frustrated with certain colours \\
\hline 4. & $\begin{array}{l}\text { Fascination with certain stimuli } \\
\text { (Fascination with pattern, lights, colors) }\end{array}$ & 1. & Is fascinated with coloured and shining objects \\
\hline 5. & $\begin{array}{l}\text { Inconsistency of perception (fluctuation) } \\
\text { (Fluctuation between hyper- and hypo-; 'in' } \\
\text { and 'out') }\end{array}$ & 1. & $\begin{array}{l}\text { May respond differently (pleasure - indifference - distress) to the } \\
\text { same visual stimuli }\end{array}$ \\
\hline \multirow[t]{5}{*}{6.} & Fragmented Perception & 1. & Resists any change \\
\hline & (Seeing in 'bits', prosopagnosia) & 2. & $\begin{array}{l}\text { Does not recognize a familiar environment if approaches it from a } \\
\text { different direction }\end{array}$ \\
\hline & & 3. & Does not recognize people in unfamiliar clothes \\
\hline & & 4. & $\begin{array}{l}\text { Selects for attention minor aspects of objects in the environment } \\
\text { instead of the whole thing (e.g. a wheel rather than a whole toy car, } \\
\text { etc.) }\end{array}$ \\
\hline & & 5. & Gets lost easily \\
\hline \multirow[t]{5}{*}{7.} & Distorted perception & 1. & Fears heights, stairs, escalators \\
\hline & (Poor/distorted depth and space perception; & 2. & Has difficulty catching ball \\
\hline & seeing 2Dd world; distortions of shape, size & & Appears startled when being approached suddenly \\
\hline & Distorted perception of body movements) & 4. & $\begin{array}{l}\text { Makes compulsive repetitive hand, head or body movements that } \\
\text { fluctuate between near and far }\end{array}$ \\
\hline & & 5. & Hits/rubs eyes when distressed \\
\hline \multirow[t]{4}{*}{8.} & 'Sensory agnosia' (difficulty interpreting a & 1. & Feels/acts blind \\
\hline & sense) & & Ritualistic behaviour \\
\hline & ('Meaning-blindness'; & & \\
\hline & Feeling/acting 'blind') & & \\
\hline
\end{tabular}




\begin{tabular}{|c|c|c|c|}
\hline 9. & $\begin{array}{l}\text { Delayed perception } \\
\text { (Delayed processing of visual stimuli) }\end{array}$ & 1. & $\begin{array}{l}\text { Response to visual stimuli is delayed (e.g. fails to close eyes when } \\
\text { the light is being switched on) } \\
\text { Any experiences are perceived as new and unfamiliar, regardless } \\
\text { of the number of time the child has experienced the same thing }\end{array}$ \\
\hline 10. & $\begin{array}{l}\text { Vulnerability to sensory overload } \\
\text { (Visual overload) }\end{array}$ & 1. & $\begin{array}{l}\text { Sudden outbursts of self-abuse/tantrums or withdrawal in response } \\
\text { to visual stimuli }\end{array}$ \\
\hline 11. & $\begin{array}{l}\text { Mono-processing (number of channels } \\
\text { working at a time) } \\
\text { (Shutting down other senses while seeing) }\end{array}$ & 1. & Does not seem to see if listening to something \\
\hline 12. & $\begin{array}{l}\text { Peripheral perception (avoidance of direct } \\
\text { perception) } \\
\text { (Peripheral vision, avoidance of eye } \\
\text { contact) }\end{array}$ & 1. & Avoids direct eye contact \\
\hline 13. & $\begin{array}{l}\text { Systems Shutdowns } \\
\text { (Visual 'whiteouts') }\end{array}$ & $\begin{array}{ll}1 . \\
2 .\end{array}$ & $\begin{array}{l}\text { Appears to be a mindless follower } \\
\text { Surprises with knowing 'unknown' information }\end{array}$ \\
\hline 14. & $\begin{array}{l}\text { Compensating for unreliable sense by } \\
\text { other senses } \\
\text { (Checking visual perception by other } \\
\text { senses) }\end{array}$ & 1. & Smells, licks, touches or taps objects \\
\hline 15. & $\begin{array}{l}\text { 'Losing oneself' in stimuli. Resonance } \\
\text { (Merging, getting in resonance with lights, } \\
\text { colours, patterns) }\end{array}$ & 1. & Seems to be absorbed with lights, colours, patterns \\
\hline 16. & $\begin{array}{l}\text { Daydreaming } \\
\text { ('Seeing' thoughts, emotions of other } \\
\text { people, events that do not relate to oneself) }\end{array}$ & 1. & Seems to know what other people (who are not present) are doing \\
\hline 17. & $\begin{array}{l}\text { Synaesthesia } \\
\text { (Seeing sounds, smell, temperature, etc.) }\end{array}$ & 1. & $\begin{array}{l}\text { Covers/rubs/blinks, etc. eyes in response to a } \\
\text { sound/touch/smell/taste movement } \\
\text { Complains about (is frustrated with) the wrong colours of } \\
\text { letters/numbers, etc. on coloured blocks, etc. }\end{array}$ \\
\hline 18. & $\begin{array}{l}\text { Perceptual memory } \\
\text { (Visual (photographic) memory) }\end{array}$ & 1. & Displays a good visual memory \\
\hline 19. & $\begin{array}{l}\text { Associative ('serial') memory } \\
\text { (Triggered by visual stimuli) }\end{array}$ & 1. & Reactions are triggered by lights, colours, patterns, etc. \\
\hline 20. & $\begin{array}{l}\text { Perceptual thinking } \\
\text { (Visual thinking (thinking in pictures)) }\end{array}$ & $\begin{array}{l}1 . \\
2 . \\
3 . \\
4 . \\
5 . \\
6 . \\
7 .\end{array}$ & $\begin{array}{l}\text { Easily solves jigsaw puzzles } \\
\text { Remembers routes and places } \\
\text { Memorizes enormous amount of information at a glance } \\
\text { Poor at mathematics } \\
\text { Learns nouns first } \\
\text { Has difficulties with adverbs and prepositions } \\
\text { Idiosyncratic patterns in language development (e.g. names one } \\
\text { thing to denote the other, etc.) }\end{array}$ \\
\hline
\end{tabular}

\section{Appendix B}

Table 2. Possible patterns of auditory experiences (adapted from (Bogdashina, 2003))

\begin{tabular}{|c|c|c|}
\hline No. & Sensory Experiences & Behaviours \\
\hline 1. & $\begin{array}{l}\text { Gestalt Perception } \\
\text { (Inability to screen out background noise) }\end{array}$ & $\begin{array}{l}\text { 1. Gets easily frustrated when trying to do something in a noisy crowded } \\
\text { room } \\
\text { 2. Does not seem to understand instructions if more than one person is } \\
\text { talking }\end{array}$ \\
\hline 2. & Intensity with which senses work & $\begin{aligned} \text { Hyper: } & \\
\text { 1. } & \text { Covers ears at many sounds } \\
\text { 2. } & \text { Is a very light sleeper } \\
\text { 3. } & \text { Is frightened by animals } \\
\text { 4. } & \text { Dislikes thunderstorm, sea, crowds } \\
\text { 5. } & \text { Dislikes haircut } \\
\text { 6. } & \text { Avoids sounds and noises } \\
\text { 7. } & \text { Makes repetitive noises to block out other sounds }\end{aligned}$ \\
\hline
\end{tabular}




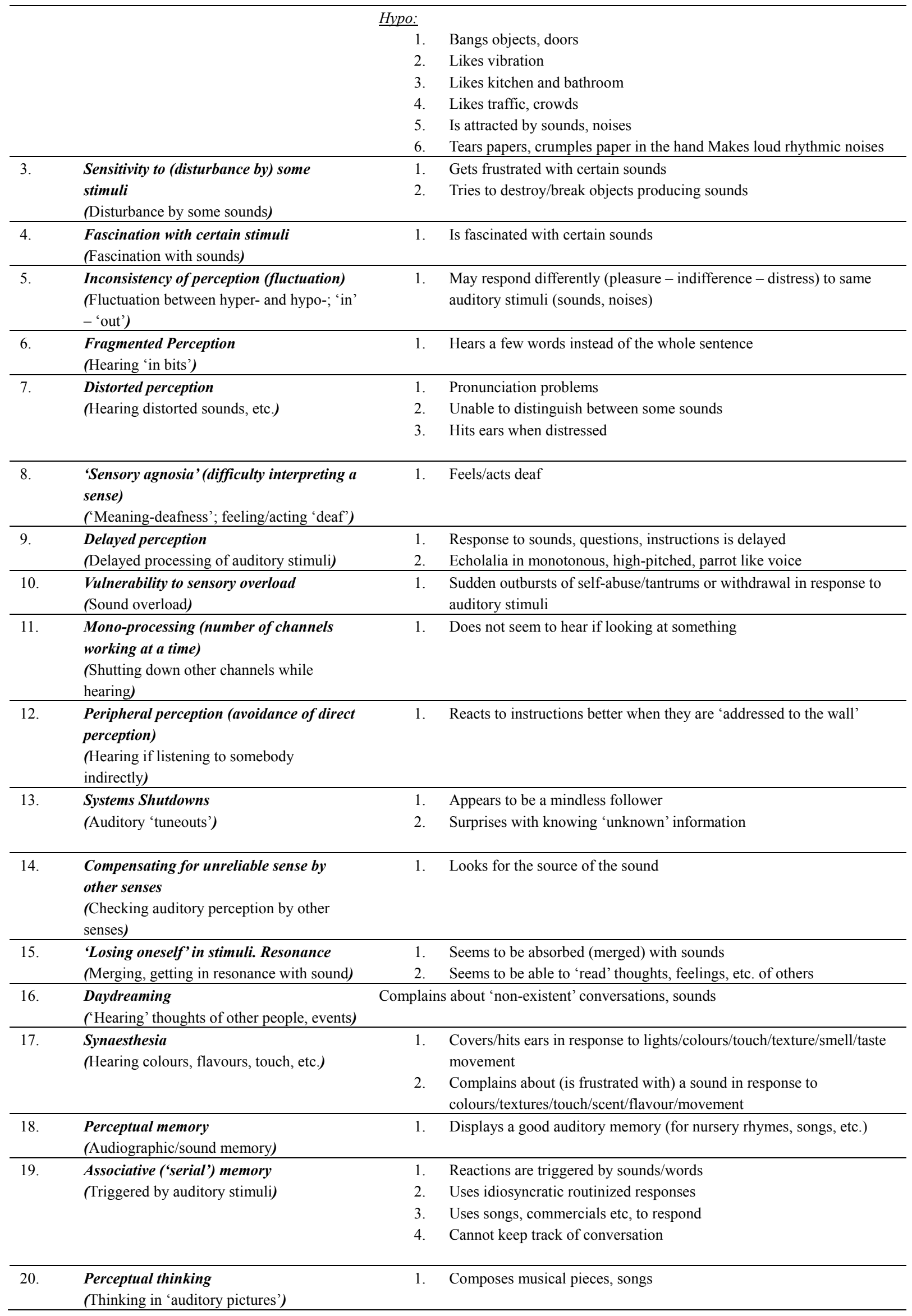




\section{Appendix C}

Table 3. Possible patterns of proprioceptive experiences (adapted from (Bogdashina, 2003))

\begin{tabular}{|c|c|c|c|}
\hline No. & Sensory Experiences & Behaviors & \\
\hline 1. & $\begin{array}{l}\text { Gestalt Perception } \\
\text { (Inability to coordinate body position and } \\
\text { movements of body parts) }\end{array}$ & 1. & Clumsy; moves stiffly \\
\hline 2. & Intensity with which senses work & 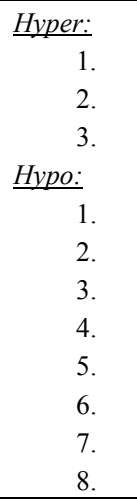 & $\begin{array}{l}\text { Odd body posturing (places the body in strange positions) } \\
\text { Difficulty manipulating small objects (e.g. buttons) } \\
\text { Turns the whole body to look at something } \\
\text { Low muscle tone } \\
\text { Has a weak grasp; drops things } \\
\text { A lack of awareness of body position in space } \\
\text { Unaware of their own body sensations } \\
\text { Bumps into objects, people } \\
\text { Appears floppy; often leans against people, furniture, walls } \\
\text { Stumbles frequently; has tendency to fall } \\
\text { Rocks back and forth }\end{array}$ \\
\hline 3. & $\begin{array}{l}\text { Sensitivity to (disturbance by) some } \\
\text { stimuli } \\
\text { (Disturbance by some body positions) }\end{array}$ & 1. & Cannot tolerate certain movements/body positions \\
\hline 4. & $\begin{array}{l}\text { Fascination with certain stimuli } \\
\text { (Fascination with certain body } \\
\text { movements) }\end{array}$ & 1. & $\begin{array}{l}\text { Is often engaged in complex body movements, esp. when frustrated } \\
\text { or bored }\end{array}$ \\
\hline 5. & $\begin{array}{l}\text { Inconsistency of perception (fluctuation) } \\
\text { (Fluctuation between hyper- and hypo-; } \\
\text { 'in'- 'out') }\end{array}$ & $\begin{array}{ll}1 . \\
2 .\end{array}$ & $\begin{array}{l}\text { May have different muscle tone } \\
\text { Pencil lines, letters, words, etc. are uneven (e.g. too tight, sometimes } \\
\text { too faint) }\end{array}$ \\
\hline 6. & $\begin{array}{l}\text { Fragmented Perception } \\
\text { (Feeling only some parts of the body) }\end{array}$ & 1. & Complains about limbs, parts of the body \\
\hline 7. & $\begin{array}{l}\text { Distorted perception } \\
\text { (Distorted perception of the body) }\end{array}$ & $\begin{array}{l}1 . \\
2 .\end{array}$ & $\begin{array}{l}\text { Difficulty with hopping, jumping, skipping, riding a tricycle/bicycle } \\
\text { Has difficulty catching balls }\end{array}$ \\
\hline 8. & $\begin{array}{l}\text { 'Sensory agnosia' (difficulty interpreting } \\
\text { a sense) } \\
\text { (Difficulty interpreting body position, } \\
\text { body sensations, etc.) }\end{array}$ & 1. & Does not seem to know what their body is doing \\
\hline 9. & $\begin{array}{l}\text { Delayed perception } \\
\text { (Delayed perception of body postures, } \\
\text { body sensations) }\end{array}$ & 1. & Very poor at sports \\
\hline 10. & $\begin{array}{l}\text { Vulnerability to sensory overload } \\
\text { (Proprioceptive overload) }\end{array}$ & 1. & Tires very easily, esp. when in noisy/bright places or when standing \\
\hline 11. & $\begin{array}{l}\text { Mono-processing (number of channels } \\
\text { working at a time) } \\
\text { (Shutting down other senses while being } \\
\text { aware of body positions) }\end{array}$ & 1. & $\begin{array}{l}\text { Does not seem to know the position of the body in space/ what the } \\
\text { body is doing, when looking at / listening to / talking }\end{array}$ \\
\hline 12. & $\begin{array}{l}\text { Peripheral perception (avoidance of } \\
\text { direct perception) } \\
\text { (Peripheral proprioceptive perception) }\end{array}$ & 1. & Has difficulty imitating / copying movements \\
\hline 13. & $\begin{array}{l}\text { Systems Shutdowns } \\
\text { (Proprioceptive 'tuneouts') }\end{array}$ & 1. & $\begin{array}{l}\text { Does not seem to know how to move their body (unable to change } \\
\text { body position to accommodate task) }\end{array}$ \\
\hline 14. & $\begin{array}{l}\text { Compensating for unreliable sense by } \\
\text { other senses } \\
\text { (Checking proprioceptive perception by } \\
\text { other senses) }\end{array}$ & $\begin{array}{l}1 . \\
2 .\end{array}$ & $\begin{array}{l}\text { Watches her/his feet while walking } \\
\text { Watches her/his hands while doing something }\end{array}$ \\
\hline 15. & $\begin{array}{l}\text { 'Losing oneself' in stimuli. Resonance } \\
\text { (Merging, getting in resonance with } \\
\text { movements) }\end{array}$ & 1. & Seems to be absorbed with body movements \\
\hline 16. & $\begin{array}{l}\text { Daydreaming } \\
\text { (Experiencing physical movements while } \\
\text { being still) }\end{array}$ & 1. & $\begin{array}{l}\text { Complains about 'non-existent' physical experiences (e.g. I am flying } \\
\text { etc.) }\end{array}$ \\
\hline
\end{tabular}




\begin{tabular}{llll}
\hline 17. & $\begin{array}{l}\text { Synaesthesia } \\
\text { (Involuntary body postures in response to } \\
\text { visual, auditory, tactile, etc. stimuli) }\end{array}$ & 1. & $\begin{array}{l}\text { Involuntary postures of the body in response to a visual/auditory } \\
\text { stimulus/ smell/ taste/ touch }\end{array}$ \\
\hline 18. & $\begin{array}{l}\text { Perceptual memory } \\
\text { (Proprioceptive memory) }\end{array}$ & 1. & $\begin{array}{l}\text { Displays a very good proprioceptive memory (e.g. understand } \\
\text { directions better if produces exact movements they have to do in } \\
\text { order to follow these directions) }\end{array}$ \\
\hline 19. & $\begin{array}{l}\text { Associative ('serial') memory } \\
\text { (Triggered by body positions, movements) }\end{array}$ & 1. & Reactions are triggered by body positions / movements \\
\hline 20. & $\begin{array}{l}\text { Perceptual thinking } \\
\text { ('Body positions, movements, images') }\end{array}$ & 1. & Mimics the actions when instructions are being given \\
\hline
\end{tabular}

\section{Copyrights}

Copyright for this article is retained by the author(s), with first publication rights granted to the journal.

This is an open-access article distributed under the terms and conditions of the Creative Commons Attribution license (http://creativecommons.org/licenses/by/4.0/). 